\title{
Caring for hospital patients with COVID-19: Quality of care in England examined by case record review
}

\author{
Author: Andrew Gibson (ed) ${ }^{\mathrm{A}}$
}

The Royal College of Physicians' COVID-19 study was conducted in 2020 as a collaboration of 19 English NHS trusts, the Association of Professional Healthcare Analysts and a data team in the Institute of Global Health Innovation at Imperial College London. The participating trusts had a combined catchment population of $\mathbf{1 0 . 4 6}$ million and looked after over 26,000 patients with SARS-CoV-2. The study involved 510 patient cases the majority of which were mortality reviews. The data were analysed both quantitatively and qualitatively and employed novel natural language processing methods. The quantitative data established that $96.5 \%$ of the care delivered was adequate, good or excellent. Poor care was uncommon. Qualitative data generated 24 common themes that were articulated by the creation of nine vignettes (four explored here). Six recommendations were created, and further analysis of specific recommendations is advised.

KEYWORDS: COVID-19, quality of care

DOI: 10.7861/clinmed.2021-0574

\section{Introduction}

A SARS-CoV-2 (COVID-19) pandemic was declared by the World Health Organization on 11 March 2020. One year later, 117 million people had been infected and approximately 2.6 million people had died from the disease. On the first anniversary of the declaration of the pandemic, over six and a half billion articles had been written about many aspects of the condition and its global effects. However, there have been limited reports of the systematic analysis of healthcare quality during the pandemic.

The Royal College of Physicians (RCP) invited NHS trusts to participate in this study in 2020, 40 trusts expressed an interest, and 19 English NHS trusts agreed to share non-identifiable patient reports of those who were treated in hospital with confirmed COVID-19. The study created thematic analysis, combined with a natural language processing technique. Vignettes, describing patient care, were constructed to articulate themes.

The quantitative elements of the study describe the demographic data, the analysis of scores given to care across the whole sample of patients and the associated subgroups.

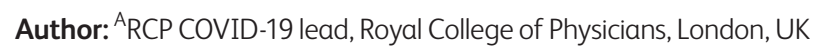

\section{Methodology}

All the centres used a structured judgement review (SJR) methodology in the construction of their reports and, in addition, collectively supplied 241 individual anonymised reports, which were subject to further analysis. The majority of the patients in this study did not survive the illness, as sites were predominantly using SJR for mortality reviews. While this was a bias in the study, this does not reflect the survival experience of those hospitalised with COVID-19 in the pandemic.

The participating centres were asked to return standardised data, in the form of modified SJR (mSJR), and describe themes that emerged from the cases that they reviewed.

This overall process is visualised in Fig 1. It included a novel approach to analysis with natural language processing. The Latent Dirichlet Allocation (LDA) methodology was used to identify statistically different topics emerging from the analysis of the subgroups identified.

\section{Results}

\section{Demographics}

All seven health regions in England were represented (described in Box 1), while the demographic data of the study sample is in Table 1.

The catchment population of the study of 10.46 million equates to approximately $19 \%$ of the population of England, which in 2019 was estimated by the Office for National Statistics as 56.23 million.

The number of hospital deaths from COVID-19 in the centres was a minimum of 6,389, which accounts for approximately one in seven acute hospital deaths from COVID-19 in 2020.

There is a range of $12 \%$ to $35 \%$ of the crude COVID- 19 mortality between the 19 centres with a median of $24 \%$. This variation is likely to be multi-factorial.

Only 18 of 510 cases (3.5\%) had an overall care score of poor. None of the cases where care was scored poorly affected the outcomes for the patients. The commonest causes of poor care are described in Box 2.

\section{Thematic analysis}

Themes generated are in Table 2 and a commentary of the theme's description was created by analysing each comment in detail and ascribing a positive or negative sentiment to the theme. 


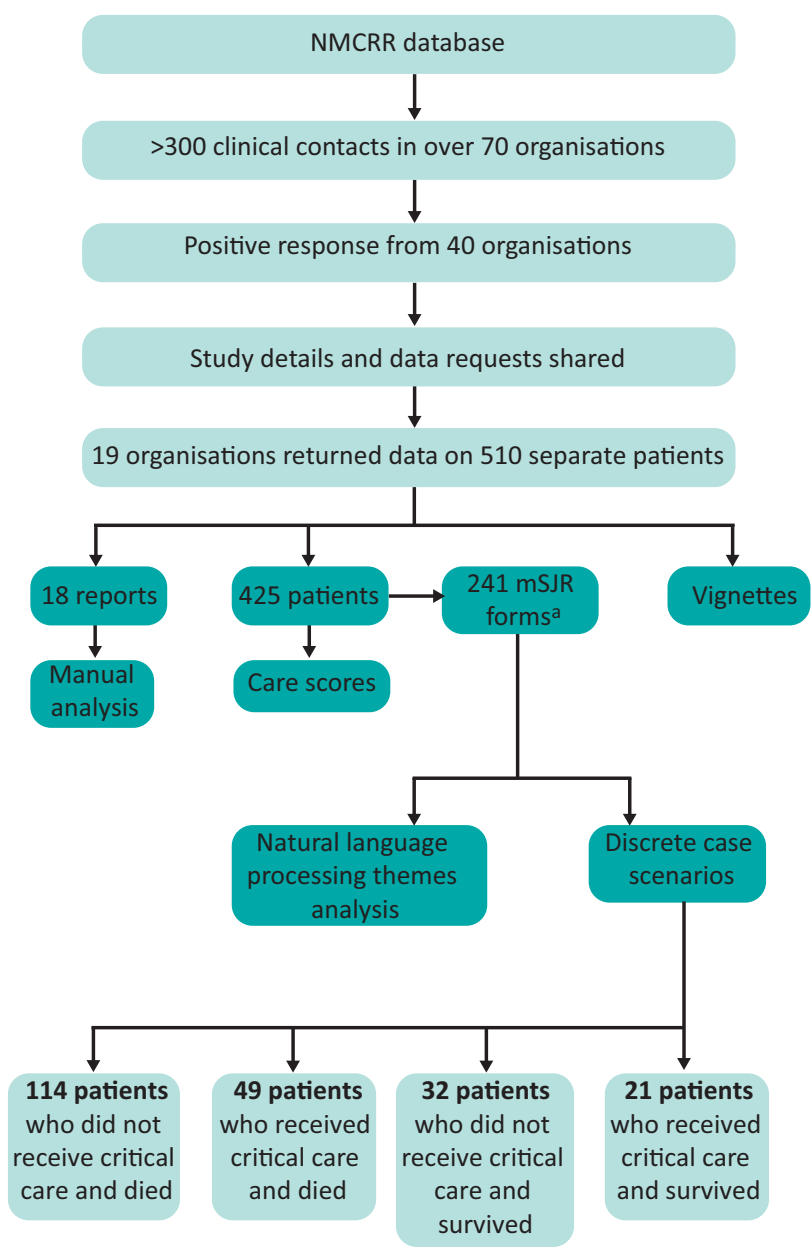

Fig 1. Overview of the study. ${ }^{a}$ This is a subset of the 425 patient cases, 216 cases were subject to analysis; NMCRR = National Mortality Case Record Review; $\mathrm{mSJR}=$ modified structured judgement review.

It is important to recognise that the negative commentary usually meant 'what could have been improved' but was not synonymous with 'poor care'. Table 2 lists these themes together with the frequency of positive or negative comments made by the centres.

As can be seen, some themes attracted both positive and negative comments implying significant variability of care quality related to that theme. In addition, some themes were mostly positive and some themes almost wholly negative.

\section{Box 1. NHS regions, cities and towns represented}

North East and Yorkshire: Barnsley, Leeds and Sheffield North West: East of England: Midlands: London:

South East: Bolton, Southport and Ormskirk Peterborough, Stamford and Norwich Lincoln, Grantham and Boston Central London, Croydon, Enfield and Camberwell

South West: Reading, Newbury, Epsom, Canterbury, Margate, Brighton and Bournemouth Bristol and north Bristol

\section{Care scores}

The care scores within each report were generated for each individual phase of care by a trained reviewer. The 425 patient cases that allowed for detailed analysis are shown in Table 3.

A subset of 216 case reviews allowed comparison of the care quality scores across four scenarios: whether the patient had received critical care or not, and whether they had survived or died. The patient characteristics of these four groups was also analysed. The care scores for these subgroups are in Table 4.

Table 4 shows that the quality of admission care across the four subgroups was of an adequate, good or excellent standard in $99 \%$ of the patients admitted, with only two cases not in this category. This suggests that despite the operational pressures, emergency departments were still able to provide high-quality care to patients with COVID-19.

In contrast to the admission phase of care, reviewers had concerns about the end-of-life care (EOLC) in those patients who died without admission to critical care, and this was different to the judgements of EOLC in a critical care setting. The proportion of the excellent care received in the ward setting was over $30 \%$, which supports the hypothesis that there is a clear inconsistency or variability in the delivery of EOLC in this study.

This subgroup analysis demonstrates that there was no care judged to be poor or very poor in the 70 patients who were admitted to critical care and either survived $(n=21)$ or died $(n=49)$. The provision of critical care was always of an adequate standard or above. For the most part, the overall care was deemed good or excellent with only one case out of 70 scored as adequate $(1.5 \%)$.

\section{Vignettes}

The common themes have been incorporated into several case vignettes (Vignettes 1-4). The vignettes reflect the outcomes described for all patient groups. A picture of the typical care

Table 1. Total catchment population, numbers of deaths and the proportions of survivors in participating

\section{centres, $\mathrm{n}=19$}

\begin{tabular}{lllll}
\hline Demographic & Number (total) & Minimum & Maximum & Median \\
Catchment population & 10.46 million & 233,303 & $1,016,000$ & 500,000 \\
Total patients with COVID-19 & 26,326 & 449 & 3,077 & N/A \\
Total deaths from COVID-19 & 6,389 & 125 & 813 & N/A \\
COVID-19 survivors & 19,937 & 390 & 2,475 & N/A \\
Crude mortality $^{a}$ & $24 \%$ & $12 \%$ & $35 \%$ & $24 \%$ \\
\hline${ }^{a}$ The crude mortality is the total number of non-survivors in a specific time frame divided by the total number of CoVID-19 cases in that time frame per organisation.
\end{tabular}


Box 2. Commonest causes of an overall care score of poor, $\mathbf{n}=18$
$>$ Poor documentation
> Poor communication
Nosocomial infection and hospital-acquired COVID-19
$>$ End-of-life care issues
$>$ Delayed assessment
$>$ Escalation decisions

received by the patients in this study is described in Vignette 1 . It includes many of the recurring positive aspects of care experienced by patients during the COVID-19 pandemic in 2020.

Table 2. Themes, with number of centres giving positive and negative comments

\begin{tabular}{|c|c|c|}
\hline Theme (abbreviated) & $\begin{array}{l}\text { Positive } \\
\text { comments } \\
\text { from centres }\end{array}$ & $\begin{array}{l}\text { Negative } \\
\text { comments } \\
\text { from centres }\end{array}$ \\
\hline End-of-life care & 18 & 15 \\
\hline Escalation decisions & 15 & 14 \\
\hline Assessment/admission & 14 & 12 \\
\hline Communication & 14 & 10 \\
\hline Senior review & 12 & 6 \\
\hline $\begin{array}{l}\text { Do not attempt } \\
\text { cardiopulmonary } \\
\text { resuscitation }\end{array}$ & 10 & 5 \\
\hline $\begin{array}{l}\text { Multidisciplinary team } \\
\text { working }\end{array}$ & 10 & 1 \\
\hline Palliative care & 11 & 2 \\
\hline Pre-emptive prescribing & 7 & 2 \\
\hline Discharge planning & 4 & 4 \\
\hline National guidance & 6 & 0 \\
\hline Documentation & 7 & 4 \\
\hline Family issues & 4 & 1 \\
\hline Challenging conversations & 3 & 3 \\
\hline Compassion & 3 & 0 \\
\hline $\begin{array}{l}\text { Medical certificate of cause } \\
\text { of death issues }\end{array}$ & 2 & 2 \\
\hline Visiting & 1 & 7 \\
\hline Treatment & 1 & 2 \\
\hline $\begin{array}{l}\text { Death quality (not end-of-life } \\
\text { care) }\end{array}$ & 1 & 4 \\
\hline Infection control & 0 & 3 \\
\hline Transfer & 0 & 8 \\
\hline $\begin{array}{l}\text { Mental Capacity Act / } \\
\text { Deprivation of Liberty } \\
\text { Safeguards }\end{array}$ & 1 & 1 \\
\hline Fluid balance & 0 & 5 \\
\hline Hospital-acquired COVID-19 & 0 & 11 \\
\hline
\end{tabular}

Vignettes 2-4 illustrate other key themes commonly described by the participating centres. The themes highlighted here involve:
$>$ EOLC management
$>$ communication and documentation
$>$ compassion
$>$ delays
$>$ escalation decisions and documentation
$>$ critical care experience
$>$ learning disability.

\section{Conclusion}

From our detailed analysis we can conclude the following

> This study presents the quality of care delivered from a large sample of patients with COVID-19 treated in representative NHS hospitals in England during the COVID-19 pandemic in 2020.

> The care delivered to patients with COVID-19 was of a high standard. It is depicted in a series of vignettes drawn from shared case studies and adapted to include common issues identified in the thematic analysis.

$>$ Learning from the review of good and excellent care, which was much more common, is equally valid to the learning derived from poor care.

> There was no evidence for differential quality of care delivery between any of the four subgroups but those patients who died and were not escalated to critical care had poorer care scores across the phases of care. This may be due to a combination of hindsight bias and the absence of negative factors in the survivors who did not, for example, experience poor EOLC.

$>$ Care judged to be poor overall was uncommon. When it did occur, it was related to EOLC issues, nosocomial infections, delays in assessment, escalation, and issues of poor communication and poor documentation.

> The experience of patients with a known learning disability appears to be different in respect of the rationale for escalation decisions. It is possible that the quality of their EOLC experience was different. Due to low case numbers, however, this finding should be treated with some caution. There were, however, clear examples where the reviewers were uncertain of the documentation and reasoning for important care decisions.

> In the context of adequate, good and excellent care, many trusts described a lack of consistency for important aspects of care delivery to patients including:

$>$ EOLC experiences

$>$ assessment in emergency departments

$>$ documentation and communication

$>$ senior review

$>$ do not attempt cardiopulmonary resuscitation decisions

$>$ discharge planning.

$>$ A multidisciplinary approach and the importance of palliative care were uniformly celebrated and key to the successful delivery of high-quality care.

$>$ Care of patients with nosocomial infections was studied in 11 trusts. These patients accounted for approximately $8 \%$ of the mortality reviews in this study. All but one of the trusts described hospital-acquired infections as negative aspects of care, and many centres had already established investigations into the causes of these infections. 
Table 3. Phases of care scores for admission, ongoing, end-of-life care / discharge and overall care

\begin{tabular}{|c|c|c|c|c|c|}
\hline & 1, very poor, n (\%) & 2, poor, n (\%) & 3 , adequate, $n(\%)$ & 4, good, n (\%) & 5 , excellent, $n(\%)$ \\
\hline Admission care, $n=360$ & $1(0.3)$ & $5(1.4)$ & $61(16.9)$ & $180(50)$ & $113(31.4)$ \\
\hline Ongoing care, $n=354$ & 0 & $19(5.4)$ & $61(17.2)$ & $175(49.4)$ & 99 (27.9) \\
\hline $\begin{array}{l}\text { End-of-life care or } \\
\text { discharge, } n=361\end{array}$ & 0 & $17(4.7)$ & $55(15.2)$ & $173(47.9)$ & $116(32.1)$ \\
\hline Overall care, $n=425^{a}$ & 0 & $18(4.2)$ & $78(18.4)$ & $213(50.1)$ & $116(27.3)$ \\
\hline \multicolumn{6}{|c|}{ The number of patient cases in each phase of care varies as some patients died rapidly in the first 24 hours. } \\
\hline \multicolumn{3}{|c|}{$\begin{array}{l}\text { There was a variation between centres of crude mortality due to } \\
\text { COVID-19 from approximately one in } 10 \text { cases to approximately } \\
\text { one in three cases. Further analysis is required to explain these } \\
\text { differences. }\end{array}$} & \multicolumn{3}{|c|}{$\begin{array}{l}\text { Using a natural language processing algorithm, as an emerging } \\
\text { qualitative technique, provided additional supporting analysis } \\
\text { to the study. This use of natural language processing will be } \\
\text { subject to further research by Imperial College London. }\end{array}$} \\
\hline
\end{tabular}

Table 4. The analysis of the four subgroups

\begin{tabular}{|l|c|c|c|c|c|}
$\begin{array}{l}\text { Phase/score } \% \\
\text { of total score }\end{array}$ & 1 & 2 & 3 & 4 & 5 \\
Very poor & Poor & Adequate & Good & Excellent
\end{tabular}

Subgroup of patients who did not receive critical care and died

\begin{tabular}{l|l|l|l|l|l|}
\hline Admission care & $0 \%$ & $0.9 \%$ & $14.8 \%$ & $58.3 \%$ & $26.1 \%$ \\
\hline Ongoing care & $0 \%$ & $5.5 \%$ & $16.5 \%$ & $56.0 \%$ & $22.0 \%$ \\
\hline EOLC/disc care & $0 \%$ & $8.8 \%$ & $14.0 \%$ & $45.6 \%$ & \\
\hline Overall care & $0 \%$ & $4.4 \%$ & $21.7 \%$ & $52.6 \%$ & $21.7 \%$ \\
\hline
\end{tabular}

Subgroup of patients who received critical care and died

\begin{tabular}{l|c|c|c|}
\hline Admission care & $0 \%$ & $0 \%$ & $6.7 \%$ \\
\hline Ongoing care & $0 \%$ & $0 \%$ & $4.4 \%$ \\
\hline EOLC/disc care & $0 \%$ & $0 \%$ & $10.4 \%$ \\
\hline Overall care & $0 \%$ & $0 \%$ & $2.2 \%$
\end{tabular}

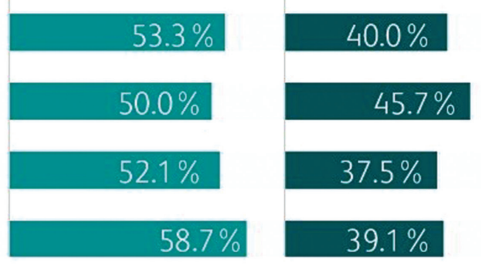

Subgroup of patients who did not receive critical care and survived

\begin{tabular}{l|l|l|l|l|l|} 
Admission care & $0 \%$ & $3.1 \%$ & $16.1 \%$ & $45.2 \%$ & \\
\hline Ongoing care & $0 \%$ & $0 \%$ & $16.1 \%$ & $61.3 \%$ & $22.6 \%$ \\
\hline EOLC/disc care & $0 \%$ & $0 \%$ & $15.6 \%$ & $50.0 \%$ & $34.4 \%$ \\
\hline Overall care & $0 \%$ & $0 \%$ & $19.4 \%$ & $54.8 \%$ & $25.8 \%$ \\
\hline
\end{tabular}

Subgroup of patients who received critical care and survived

\begin{tabular}{|c|c|c|c|c|c|}
\hline Admission care & $0 \%$ & $0 \%$ & $0 \%$ & $36.9 \%$ & $63.2 \%$ \\
\hline Ongoing care & $0 \%$ & $0 \%$ & $0 \%$ & $50.0 \%$ & $50.0 \%$ \\
\hline EOLC/disc care & $0 \%$ & $0 \%$ & $0 \%$ & $45.0 \%$ & $55.0 \%$ \\
\hline Overall care & $0 \%$ & $0 \%$ & $0 \%$ & $57.1 \%$ & $42.9 \%$ \\
\hline
\end{tabular}




\section{Vignette 1. Typical ward care received}

A 79-year-old woman was admitted to hospital at 9pm following a fall and increasing shortness of breath. She was seen rapidly by a consultant within 2 hours of admission and COVID-19 was considered to be the diagnosis.

A rapid decision was reached that she should not be escalated to intensive treatment unit. This was well-documented and with the full agreement of the multidisciplinary team (MDT) and patient. All subsequent documentation was of a high standard. Contact with relatives was completed in a timely manner. While receiving ward care, the patient was referred to the appropriate specialties with gastroenterology, diabetes and renal teams all involved. There was good awareness of the patient's multiple conditions. Nursing care was of a high standard, as was associated documentation. Blood sugars were well-documented. Chest $X$-ray on admission showed mild bilateral patchy shadowing. The COVID-19 swab was positive and the patient was managed with good infection prevention and control on a COVID-19 ward. There was senior involvement and MDT input at all stages and timely review from all specialties. She experienced a short period of hypoactive delirium while on the ward, which her relatives found distressing but was very well managed by the team.

The patient developed a low mood with some anxiety elements in the subsequent days and was mildly deconditioned, which was minimised by high-quality physiotherapy input. She was discharged to the community for further recovery and rehabilitation prior to being transferred to her previous residence.

\section{Recommendations}

$>$ Hospitals and teams that have delivered excellent care during the pandemic should analyse the factors that have enabled this to happen. They could share the learning from the key findings, locally or nationally, to support more consistent quality of care in the future and to raise awareness across the NHS and with the general public.

> Healthcare professionals and organisations should strive to reduce the variation in care in key areas including:

$>$ EOLC in hospital

$>$ early assessment in acute care presentations
Vignette 3. Compassion in end-of-life care delivery

An 82-year-old man was admitted via the emergency department with shortness of breath, chest pain and cough. He was seen rapidly by the respiratory consultant. The patient had chronic obstructive pulmonary disease with limited exercise tolerance. A diagnosis of likely COVID-19 with possible superadded bacterial infection and probable element of heart failure was made. Following well-documented discussions with the patient, it was agreed that the patient was probably in the last days of life and that he would not be a candidate for invasive ventilation. There was rapid input from palliative care and the patient was given pre-emptive medication as needed.

Due to the high incidence of COVID-19, his family did not wish to visit. However, the foundation year-2 doctor and nursing staff took turns to sit with the patient and read messages that the family had sent. It should be recognised that during the height of the pandemic, staff went above and beyond to help comfort patients in lieu of family.

> documentation and communication

$>$ senior review and decision making

$>$ treatment escalation planning, conversations and documentation

$>$ discharge planning

> particular focus should be given to reducing variation for those with learning disabilities in these areas.

> The guidance and standards published by the RCP covering many of these areas should be implemented and followed more consistently.

> All NHS organisations are encouraged to pay particular attention to the quality of care, decision making, communication and documentation that is required for vulnerable people, including those with learning disabilities.

> The NHS should further explore the reasons for the range of hospital mortality between areas during the COVID-19 pandemic.

> The RCP and Imperial College London will further explore the role of natural language processing in the qualitative analysis of structured case record reviews.

\section{Vignette 2. Poor communication}

A 57-year-old man was admitted to the emergency department from a hostel via his general practitioner. Initial and ongoing care was of a high standard, but the patient deteriorated and died rapidly. He had no next of kin with him at death.

Communication with the patient's family was poor during the whole period; there was no evidence from review of the medical records of any contact with them, despite there being a contact number in the medical record of a sister. The hostel manager contacted the family to inform them of the death and they then telephoned the ward with questions. This may have resulted in additional distress to the family. While the care of the patient was of a high standard there was clear room for improvement in communication with his next of kin.

\section{Vignette 4. Documenting decisions, delays and}

\section{escalation}

A 46-year-old woman with a known learning disability was admitted acutely from her sheltered and warden-controlled accommodation where she was fully independent. Her body mass index was $34 \mathrm{~kg} / \mathrm{m}^{2}$. She was seen in the emergency department (ED) with shortness of breath and it was assumed that she had COVID-19. She was not reviewed by the admitting team for 12 hours, but an X-ray carried out by the ED team showed typical features of COVID-19 pneumonia.

There was evidence of a discussion about do not attempt cardiopulmonary resuscitation on the post-take ward round, but it was not clear and not documented on what basis the decision to restrict to ward-level care was made. 


\section{Full report}

The full report can be accessed on the RCP website:

www.rcp.ac.uk/projects/outputs/caring-hospital-patients-covid-19
Address for correspondence: Dr Andrew Gibson, $11 \mathrm{St}$ Andrews Place, Regent's Park, London NW1 4LE, UK. Email: andrew.gibson7@nhs.net 